\title{
Multiple-choice and Error Recognition Tests: Effects of Test Anxiety on Test Performance
}

\author{
Nur-ihsaan Nihae (Corresponding author) \\ M.A. student, Department of Languages and Linguistics, Faculty of Liberal Arts \\ Prince of Songkla University, Hat Yai Campus, Songkla, Thailand \\ E-mail: Nihae.nur@gmail.com
}

\begin{abstract}
Thanyapa Chiramanee
Assoc. Prof. Dr., Department of Languages and Linguistics, Faculty of Liberal Arts

Prince of Songkla University, Hat Yai Campus, Songkla, Thailand

E-mail: thanyapa.c@psu.ac.th
\end{abstract}

Received: June 4, 2014 Accepted: June 22, 2014 Published: June 22, 2014

doi:10.5296/ijele.v2i2.5854 URL: http://dx.doi.org/10.5296/ijele.v2i2.5854

\begin{abstract}
The present study aimed to investigate the use of multiple-choice test and error identification tests in testing grammar to find out the effect of test anxiety produced by the two types of test formats on learners' performance. A sample of 36 students was randomly selected from the total population of 469 students who were in Matthayom 5 at Narathiwat School, Narathiwat province, Thailand. The research instruments were grammar knowledge test, teaching plans with the use of multiple-choice and error recognition exercises, and test anxiety questionnaire. The results revealed that the two subjects' group had quite the same level of test anxiety produced by multiple-choice and error recognition. However, after 15 weeks of treatment, the two subject groups' test anxiety showed some differences which could be observed, though non-significantly. That is the test anxiety produced by the test format the subjects were trained reduced. Moreover, the results revealed a significant and negative relationship between test anxiety produced by error recognition and pre-treatment score. However, no significant relation between their scores on error recognition format and test anxiety was found after the treatment.
\end{abstract}

Keywords: Multiple-choice test, Error recognition test, Test anxiety 


\section{Introduction}

A language test is important for language learning. Testing is a topic of employing data to verify the proof of learning (McNamara, 2000). There is a strong relationship between a language test and language learning. A test reinforces learning and evaluates a language performance of the learners (Heaton, 1988). For Kaewmala (2012), good tests should determine children's competence to apply knowledge to their everyday life. Tests are instruments to assess not only students' scholastic performance but also the performance of schools and teachers. Tests can demonstrate the testers' quality and the education system as a whole. Thus, one characteristic of a good test is that the method has little effect on the trait. Therefore, Bechman (cited in Khoii and Shamsi, 2010) emphasizes the need of developing a framework for delineating the specific features or facets of the test method in order to understand variation in language performance.

It is widely accepted that one of the factors interacting in the process of testing is a test method which refers to the specific procedure or technique that is used to assess the trait which refers to the knowledge being measured (Shohamy, 1984).

Test format influences students' reaction to the test, including test anxiety. A number of researchers have revealed that test type is one of the factors that leads to test anxiety (Young, 1984 cited in Trimoni and Shahini, 2011; Trimoni and Shahini, 2011; Murray, 1985 cited in Madson et al., 1991). Some students become anxious during exams that require them to demonstrate their knowledge in ways in which they do not feel comfortable. For example, some students panic when they have to take an essay test. Others become anxious over oral exams.

Murray (1985, cited in Madson et al., 1991) proposes that test anxiety is produced by perceptions of item difficulty, time limitation, lack of familiarity with test type, ambiguity in item. Young (1999 cited in Trimoni and Shahini, 2011) posits that students feel anxious when they take the test question type which they have no experience. So, unfamiliarity with test format is one of many factors producing test anxiety (Scott and Madson, 1983 cited in Madson et al., 1991).

Different definitions of test anxiety have been proposed by many scholars. According to Spielberger (1983, cited in Nemati and Habibi, 2012), test anxiety is the subjective feeling of tension, apprehension, nervousness and worry associated with an arousal of the autonomic nervous system. For Chavous (2008), test anxiety can be rigorously defined as a feeling of apprehension and discomfort accompanied by cognitive difficulties during the test. Cassady and Johnson (2002) propose that test anxiety involves at least two components: (a) a pattern of physiological hyper arousal that may include physical changes and complaints such as increased heart rate, blood pressure, etc., and (b) a cognitive obstruction or disorganization of effective problem-solving and cognitive control, including difficulty in thinking clearly. A proposed third factor, Chavous (2008), that has received less attention is social humiliation, referring to one's concern and awareness that others may negatively view their performance.

There have been many principles of anxiety proposed by researchers, for example, Alpert and 
Haber (1960 cited in Horwitz, 1999), Simpson et al., (1995 cited in Birjandi and Alemi, 2010). Among these many principles, Alpert and Haber's principle of anxiety is widely known and well accepted among scholars in the field of anxiety. Their principles of anxiety consist of two categories: Facilitating and deliberating anxiety. Facilitating anxiety is an increase in drive level which results in improved performance while debilitating anxiety is an increase in arousal or drive level which leads to poor performance.

Research has been done on the effect of test anxiety on students' test performance. There is a broad agreement in the empirical evidence that test anxiety is associated with lower academic performance (i.e., deliberating anxiety). For example, Hambree (1988 cited in Hancock, 2001) examined the research on the effects of test anxiety on academic performance and found that test anxiety caused poor performance. Zatz and Chassin (1985 cited in Hancock, 2001) investigated the relationship between test anxiety and test performance. The results showed that the students with high test anxiety performed more poorly on the test than those students with low or medium anxiety. Moreover, facilitative anxiety was demonstrated by many researchers. For example, Birjandi and Alemi (2010) investigated the relationship between test anxiety and test performance and found that there was a positive correlation between test anxiety and test performance. They concluded that test performance can be improved by slight anxiety.

Based on the discussions above, one of the sources of anxiety is unfamiliarity with test format. Many types of test formats are used in testing, which can be classified into two general types. The first type is the objective test which requires the students to supply a word or two, or to select the correct answer from among a limited number of alternatives. Examples of objective tests are short answer, completion, true-false or alternative response, matching and multiple-choice test. The other type is subjective test which permits the learner to select, organize and present their answer in essay form, including extended response type and restricted response type (Grounlund, 1971; Henning, 1987 cited in Hughes, 1989).

Multiple-choice format has been very familiar in language learning because the format has been used in schools and university tests. There are many advantages of using multiple-choice in language testing. Multiple-choice tests are fast, easy and they can be scored objectively (Bailey, 1990 cited in Khoii and Shamsi, 2010). Further, they can be used to narrowly test one discrete area of knowledge or skill (Lado, 1961 cited in Currie and thanyapa, 2010) and can provide diagnostic information to teachers by analysis of incorrect option selection (Nitko, 1983 cited in Currie and thanyapa, 2010). Additionally, the demands of an educational context with large numbers of test takers and the need for fast marking might make the use of multiple-choice format unavoidable (Khoii and Shamsi 2010). Liu (2007 cited in Currie and thanyapa, 2010) also noted the main format used in Chinese middle school and university tests is multiple-choice items.

In Thailand, multiple choice tests have been used extensively in many national tests including the university admission testing system. In 2005 and 2007 respectively, the Ordinary National Education Test (O-NET), the tests for grade 6, grade 9, and grade 12 students to assess their academic proficiency and General Aptitude Test (GAT), which are the test for university 
admission, first introduced error recognition test format, particular in its grammar parts. However, tests of other parts such as reading comprehension and communication skills are still in multiple-choice format (The National Institute of Educational Testing Service, 2009). Error recognition items have become more popular; many Thai standardized tests such as Chulalongkorn University Test of English Proficiency (CU-TEP), Prince of Songkla University Test of English Proficiency (PSU-TEP) and Thammasat University Graduate English Test (TU-GET) employ error recognition format.

Error recognition items, aiming to measure students' grammatical knowledge and indirectly test writing skills, consist of a complete sentence, with four underlined part, one of which is grammatically wrong. The error identification format has been perceived as being convenient, efficient and economical for teachers to prepare and construct. However, there are some people who are against the use of error identification techniques because of its emphasis on more negative aspects of language learning. Heaton (1990 cited in Khoii and Shamsi, 2010), for example, believes that in practice, error identification method does not work very well because many students tend to regard every sentence as having an error. Moreover, error identification items are demanding, requiring a different kind of thinking, and students have to read and consider each response option carefully and draw on various kinds of grammatical knowledge to respond correctly (Geregly, 2007 cited in Khoii and Shamsi, 2010). Although there are many limitations associated with error identification format, it is commonly used in many standardized tests such as SAT (Scholastic Assessment Tests), TOEIC and many widely accepted tests in Thailand such as CU-TEP, PSU-TEP and TU-GET.

Since there have been a relatively small number of studies on the effect of test formats on students' performance, let alone Thailand, this study aimed to investigate the use of multiple-choice test and error identification tests in testing grammar to find out the effect of test anxiety produced by the two types of test formats on learners' performance.

\section{Research Questions}

2.1 Do the multiple-choice test and error recognition test produce the same extent of test anxiety?

2.2 Is there any relationship between test anxiety produced by two test formats and test takers'performance?

\subsection{Does practice effect reduce test anxiety?}

\section{Purpose of the Study}

The purpose of this study was to investigate the use of multiple-choice test and error identification tests in testing grammar knowledge to find out the effect of test anxiety produced by the two types of test format on learners' performance. It was hoped that the outcome of the study would provide useful information about the use of the two test formats to test grammar knowledge; the students might have problems caused by test format anxiety which may influence their performance on the tests. In addition, the findings that test anxiety can be reduced by practice effect might be useful for teachers by familiarizing their students 
by repeated use of the test formats.

\section{Research Methodology}

\subsection{Participants}

The participants in this study were 36 students randomly sampled from the total population of 469 students who were in Matthayom 5 at Narathiwat School, Narathiwat province, Thailand.

\subsection{Research Instruments}

\subsubsection{Grammar Knowledge Test}

A test was designed to investigate the students' grammar knowledge. There were two main parts, one part consisting of 30 multiple-choice items and the other part of 30 error identification items. The total score of the test was 60 marks. The test was administered twice; first as a pre-test and again, after the treatment as a post-test. The pre-test scores on the grammar knowledge test were used to divide the 36 subjects into two groups, 18 subjects for each. The mean scores of these two groups were not significantly different. $(\bar{x}=35.78$, S.D. $=3.00$ and $\quad \bar{x}=35.00$, S.D. $=3.45$, respectively).

\subsubsection{Teaching Plans}

Thirty teaching plans were designed to develop the subjects' grammar knowledge. Fifteen teaching plans with the use of multiple-choice exercises and tests were used with one subject group, who would be referred to hereafter as multiple-choice group (MC group). Another fifteen teaching plans with the use of error recognition exercises and tests would be used with the other subject group, referred to as error recognition group (ER group). Despite the different test formats used in the teaching plans, the fifteen teaching plans with the error identification version and those with multiple-choice version were aimed to develop the same 15 grammar points, i.e. present simple tense, past simple tense, subject verb agreement, preposition, article and so on. Each experimental group spent 15 weeks, two hours a week for one teaching plan, a total of 30 hours for 15 teaching plans.

\subsubsection{Test Anxiety Questionnaire}

A test anxiety questionnaire was adapted, based on Scott's (1986) and Cassady and Johnson's (2004) to measure the degree of test anxiety produced by multiple-choice and error recognition test formats before and after treatment period. The questionnaire consisted of 20 items related to how one generally feels when taking the two test formats. For example, before taking this test, I am so nervous; I worry while I am taking this test, and so on. This questionnaire was designed on a 5-point Likert scale ranging from "Strongly Disagree" to "Strongly agree" with values 1-5 assigned to them respectively. All the items were written in Thai to ensure that the intended meaning was conveyed.

\subsection{Procedure}

In the first week of the study, the 30-item grammar knowledge test was administered as the pre-test to measure the 36 subjects' knowledge of grammar and their homogeneity in terms of 
English grammar knowledge. Right after taking each test format the subjects rated test anxiety toward each test format. The scores on the grammar knowledge test were used to divide the subjects into two experimental groups.

The subjects were divided into two groups; error identification group and multiple-choice group. Both groups were taught using 15 teaching plans employing error recognition exercises and multiple-choice exercises to develop their grammar knowledge. Before new grammar points were introduced through a new teaching plan, the grammar point just taught in the previous teaching plan was tested using two different test formats, error identification for error identification group and multiple-choice for multiple-choice group.

After 15 weeks, the same grammar knowledge test consisting of 30 items of multiple-choice and 30 items of error identification was given as a post-test to measure students' knowledge of grammar. Test anxiety questionnaire of the two test formats was also administered with exactly the same procedure as the pre-treatment one.

\section{Results and Discussion}

Table 1 compares each subject group's test anxiety produced by multiple-choice and error recognition test.

Table 1. Two subject groups' test anxiety produced by multiple-choice and error recognition formats

\begin{tabular}{|c|c|c|c|c|c|c|c|c|}
\hline \multirow{3}{*}{ Group } & \multirow{3}{*}{$\begin{array}{l}\text { Grammar } \\
\text { knowledge test }\end{array}$} & \multicolumn{4}{|c|}{ Level of test anxiety } & \multirow{3}{*}{ Decrease } & \multicolumn{2}{|c|}{$\begin{array}{l}\text { Paired-sample } \\
\text { t-test }\end{array}$} \\
\hline & & \multicolumn{2}{|c|}{$\begin{array}{l}\text { Before } \\
\text { treatment }\end{array}$} & \multicolumn{2}{|c|}{$\begin{array}{l}\text { After } \\
\text { treatment }\end{array}$} & & t-value & 2-tail \\
\hline & & $\bar{x}$ & S.D. & $\bar{x}$ & S.D. & & & \\
\hline \multirow{2}{*}{$\begin{array}{l}\text { MC } \\
\text { group }\end{array}$} & MC version & 3.10 & 0.38 & 2.83 & 0.72 & 0.27 & -1.479 & 0.158 \\
\hline & ER version & 3.30 & 0.37 & 3.21 & 0.60 & 0.09 & -0.630 & 0.537 \\
\hline \multirow{2}{*}{$\begin{array}{l}\text { ER } \\
\text { group }\end{array}$} & MC version & 3.14 & 0.45 & 3.02 & 0.64 & 0.12 & -0.596 & 0.559 \\
\hline & ER version & 3.36 & 0.60 & 3.13 & 0.73 & 0.23 & -0.897 & 0.382 \\
\hline
\end{tabular}

Table 1 shows quite the same extent of subjects' test anxiety produced by two test formats before treatment. The level of test anxiety produced by multiple-choice of the MC group and the ER group were 3.10 and 3.14, while that produced by error recognition were 3.30 and 3.36, respectively. Both subjects group had higher level of anxiety produced by error recognition than multiple-choice, though non-significant.

For the MC group, after 15 weeks of treatment, the test anxiety of the MC group produced by multiple-choice reduced from 3.10 to 2.83 , a non-significant decrease of 0.27 , and their test 
anxiety level produced by error recognition reduced from 3.30 to 3.21 , a non-significant decrease of 0.09 . There was a greater decrease in test anxiety produced by multiple-choice, a test format they were trained with during the 15 weeks of treatment, than the anxiety produced by error recognition part, the test format they were not trained with.

For the ER group, the test anxiety produced by multiple-choice reduced from 3.14 to 3.02, a non-significant decrease of 0.12 , and their test anxiety level produced by error recognition reduced from 3.36 to 3.13, a non-significant decrease of 0.23 There was a greater decrease in test anxiety produced by error recognition, a test format they were trained with during the 15 weeks of treatment, than the anxiety produced by multiple-choice.

The findings demonstrated the influence of practice effect on test anxiety. The 15-week treatment given to the MC and ER subject groups helped familiarize the subjects with the test format in questions, which in turn, helped reduce their anxiety level. It is widely accepted that test anxiety affects test performance (Cassady and Johnson, 2002 cited in Rana and Mahmood, 2010), which would be discussed in the following section.

The findings about the reduction of test anxiety in both subject groups in the present study after 15 weeks of treatment may offer useful information on practice effect which helped reduce the subjects' anxiety. This is in line with what Madson and Murray (1984 cited in Scott, 1986) and Young (1999 cited in Trimoni and Shahini, 2011) who suggest that unfamiliarity with question types or exam formats can cause test anxiety. Therefore, Alcala (2002 cited in Trimoni and Shahini, 2011) proposes that in order to reduce test anxiety which influences students' performance, teachers can familiarize students with the exam format.

Another interesting finding of this present study was about the relationship between test anxiety and test performance. To establish a relationship between the subjects' performance and the test anxiety, the 36 subjects' scores in the multiple-choice part and error recognition part of the grammar knowledge test and their anxiety produced by the two test formats were analyzed using Product Moment Correlation Coefficient Test. The results of the analysis are presented in Table 2 below.

Table 2. Relationship between test scores and test anxiety

\begin{tabular}{llll}
\hline \multirow{2}{*}{ Group } & $\begin{array}{l}\text { Scores on } \\
\text { grammar test }\end{array}$ & the & \multicolumn{2}{l}{ Level of test anxiety } \\
\cline { 3 - 4 } & MC format & 0.098 & After treatment \\
\hline MC group & ER format & -0.089 & 0.25 \\
& MC format & 0.253 & -0.392 \\
ER group & ER format & $-0.648^{* *}$ & -0.155 \\
& & & -0.058 \\
\hline
\end{tabular}

** Significant at the .01 level 
For the MC group, it was found that the correlation between their pre-treatment score on multiple choice format and test anxiety produced by multiple-choice was 0.098 , and the correlation between the pre-treatment error recognition scores and the test anxiety produced by error recognition was -.089 . This indicated that there was no significant relationship between the MC group's test performance and test anxiety produced by the two test formats. The same case was found with their post treatment scores $(r=0.25, r=-0.395)$

For the ER group, their pre and post treatment test scores on the multiple choice format were not significantly related to the test anxiety produced by the multiple choice test $(r=0.0253, r$ $=-0.155)$. However, their pre-treatment test score on error recognition part of the test was significantly and negatively related to their anxiety produced by this format $(r=-.648, p<$ 0.01 ), suggesting that the higher the test anxiety produced by the error recognition type, the lower their test scores on this test format, and vice versa. Nonetheless, no significant relation between their scores on error recognition format and test anxiety was found after the treatment $(r=-0.058)$. This means that, after 15 weeks of treatment with error recognition exercises, they became more familiar with this test format so their anxiety decreased. This might confirm the prominent role of practice effect discussed previously.

The significant relationship between test anxiety produced by error recognition format and the ER group's test performance, i.e. the higher the test anxiety, the lower the test scores and vice versa is referred to as deliberative anxiety; this type of anxiety adversely affects test taker's performance. Deliberative anxiety takes different forms to harm learners' performance in various ways, through worry and self-doubt and reduces reducing participation and creating overt avoidance of the language. The debilitating physiological effects of anxiety interfere with individuals' performance and lead to poor academic performance (Tryron, 1980 cited in Chen, 2007).

Some studies have revealed deliberative anxiety on the students' performance; Rana and Mahmood (2010), for example, conducted a study to explore the relationship between test anxiety and academic achievement of students at the post graduate level. They were found that a significant negative relationship exists between test anxiety scores and students' achievement scores. Trifoni and Shahini (2011) also studied the effects of test anxiety on test performance of university students. They also found deliberative anxiety and its effects on their subjects' performance.

This present study supported previous research which has revealed a negative relation between test anxiety and students' performance (e.g., Hambree, 1988 cited in Hancock, 2001; Hancock, 2001; Chapell et al., 2005; Trifoni \& Shahini, 2011). All these researchers have reached the conclusion that students performance and test anxiety level have a reverse ratio, meaning that when test anxiety level increases, students' performance decreases and vice versa.

\section{Concluding Remarks and Recommendations for Further Studies}

This study has provided useful information on test anxiety produced by test formats. It also demonstrated the practice effect of test format and the relationship between test anxiety 
produced by multiple-choice and error recognition and test performance. The results of the present study have shown that in the pre-treatment, the two subjects' group had quite the same level of test anxiety produced by multiple-choice and error recognition. However, after 15 weeks of treatment, the two subject groups' test anxiety showed some differences which could be observed, though non-significantly. That is the test anxiety produced by the test format the subjects were trained reduced, indicating that the test practice as a result of the subjects being taught grammar points using multiple-choice and error recognition formats reduced their anxiety.

Moreover, the present study revealed a significant and negative relationship between test anxiety produced by error recognition and pre-treatment score. That is, the higher the test anxiety a test taker had on the error recognition type, the lower his test score was. This relation is referred to as deliberative anxiety; this type of anxiety adversely affects test taker's performance. However, no significant relation between their scores on error recognition format and test anxiety was found after the treatment. In other words, anxiety produced by error recognition test no longer affected the test performance of the ER group after treatment. The non-significant relationship between test anxiety produced by error recognition and test performance might be a result of practice effect of 15 weeks of treatment. In addition, the finding of this present study seemed to suggest that practice effects exerted their influence on unfamiliar test format (i.e. error recognition) but on familiar test format (i.e. multiple-choice).

The results of this present study will also be useful for classroom teachers who consider introducing new or unfamiliar test formats in the evaluation process. In order to reduce test anxiety that might be caused by unfamiliar test formats, teachers can familiarize the students with the test formats by a repeated use of the test formats through classroom activities such as exercises or quizzes. When the students are familiar with the test format, then that format can be used in the evaluation process to make sure that the students' performance will not be affected by test anxiety caused by the test formats used to evaluate their knowledge.

For further investigation, research would need to be conducted on the use of multiple-choice test and error identification tests in testing grammar knowledge to find out the effect of test anxiety produced by the two types of test formats with learners at different language proficiency levels and in different educational contexts. In addition, more research instruments such as observation, interview, etc. should be included in future studies in order to get in-depth information about test anxiety. This may also allow researchers to discover other interesting factors that may lead to test anxiety and to develop a viable tool for reducing test anxiety.

\section{Acknowledgement}

The research is financed by Asian Development Bank. No. 2006-A171. Thanks for Prof. AAA BBB, World Technology University.

\section{References}

Birjandi, P., \& Alemi, M. (2010). The Impact of Test Anxiety on Test performance among Iranian EFL Learners. BRAIN. Broad Research in Artificial Intelligence and Neuroscience, 4, 
44-58. Retrieved from http://www.edusoft.ro/brain/index.php/brain/article/view/131

Cassady, J., \& Johnson, E. (2002). Cognitive Test Anxiety and Academic Performance. $\begin{array}{llll}\text { Contemporary } & \text { Educational 270-295. }\end{array}$ http://dx.doi.org/10.1006/ceps.2001.1094

Chapell, M. et al. (2005). Test Anxiety and Academic Performance in Undergraduate and Graduate Students. Journal of Education Psychology, 97, 268-274. http://dx.doi.org/10.1037/0022-0663.97.2.268

Chavous, T. (2008). Evaluation (Test) Anxiety. Psychology of Classroom Learning, 1, 387-390. Retrieved from http://www.edb.utexas.edu/robinson/danr/Evaluation_anx.pdf

Currie, M., \& Thanyapa, C. (2010). The effect of the multiple-choice item format on the measurement of knowledge of language structure. SAGE journal, 471-49. http://dx.doi.org/10.1177/0265532209356790

Chen, M. (2007). Test Anxiety Reading Anxiety and Reading Performance among University English as Second Language Learners. MA. Thesis, Ming Chuan University, Tai Pei: Taiwan.

Hancock, D. R. (2001). Effects of test anxiety and evaluative threat on students' achievement and motivation. The Journal of Educational Research, 284-290. Retrieved from http://www.jstor.org/discover/10.2307/27542336

Heaton. (1988). Writing English Language Test. (New ed.). New York: Longman.

Hughes. (1989). Testing for Language Teachers. New York: Cambridge.

Horwitz, \& Young. (1999). Language Anxiety from Theory and Research to Classroom Implications. New York: Peason.

Kaewmala. (2012). The education failure- part 2: Test score, standards and accountability. [Online] Available: http://asiancorrespondent.com/76877/thai-education-part-2-test-scoresstandards-and-accountability/ (Feb 27, 2012).

Khoii, R., \& Shamsi, N. (2010) .The Effect of the Method on the Trait: Investigating theFunction of No-Error Option in Grammar Error-Identification Items in Admission Tests. Iranian EFL Journal, 7(2), 166-178. Retrieved from http://www.academia.edu/1051958/ TheEffectoftheMethodontheTraitInvestigatingtheFunctionofNo-Error

Madsan, S. et al. (1983). Techniques in testing. New York: Oxford.

McNamara. (2000). Language Testing. New York: Oxford.

Nemati, A., \& Habibi, P. (2012). The effect of practicing pranayama on test anxiety and test performance. Indian Journal of Science and Technology, 5, 2645-2650. Retrieved from http://www.indjst.org/index.php/indjst/article/viewFile/30438/26366

Rana, R., \& Mahmood, N. (2010). The Relationship between Test anxiety and Academic Achievement. Bulletin of Education and Research, 32(2), 63-74. Retrieved from http://pu.edu.pk/images/journal/pesr/PDF-FILES/4-Rizwan\%20Akram\%20Rana.pdf 


Mll Macrothink

Scott, M. (1986). Student affective reactions to oral language tests. Language Testing, 3(1), 99-118. http://dx.doi.org/ 10.1177/026553228600300105

Shohamy, E. (1984). Does the testing method make a difference? The case of reading comprehension. Language Testing, 1(2), 147-170. http://dx.doi.org/10.1177/026553228400100203

The National Institute of Educational Testing Service. (2009). About O-NET. [Online] Available: http://www.niets.or.th/upload-files/uploadfile/5/5113f2fc40d9b7ccbf26972226c1a 536.pdf (May 25, 2009).

Trimoni, A., \& Shahini, M. (2011). How Does Exam Anxiety Affect the Performance of University Students?. Mediterranean Journal of Social Sciences, 2(2), 93-100. Retrieved from http://www.mcser.org/images/stories/2 journal/mjssmay2011/9.pdf

\section{Copyright Disclaimer}

Copyright for this article is retained by the author(s), with first publication rights granted to the journal.

This is an open-access article distributed under the terms and conditions of the Creative Commons Attribution license (http://creativecommons.org/licenses/by/3.0/). 